\title{
Realizing Health Reform's Potential Implementing the Affordable Care Act: State Action to Establish SHOP Marketplaces
}

The mission of The Commonwealth Fund is to promote a high performance health care system. The Fund carries out this mandate by supporting independent research on health care issues and making grants to improve health care practice and policy. Support for this research was provided by The Commonwealth Fund. The views presented here are those of the authors and not necessarily those of The Commonwealth Fund or its directors, officers, or staff.

For more information about this study, please contact:

Sarah J. Dash, M.P.H.

Research Fellow

Center on Health Insurance Reforms

Georgetown University Health Policy Institute sd850@georgetown.edu

To learn more about new publications when they become available, visit the Fund's Web site and register to receive e-mail alerts.

Commonwealth Fund pub. 1735

Vol. 3

\section{Sarah J. Dash, Kevin W. Lucia, and Amy Thomas}

Abstract: The Affordable Care Act seeks to help small employers offer coverage by reforming the small-group market and establishing Small Business Health Options Program (SHOP) marketplaces. Seventeen states and the District of Columbia chose to operate their own SHOP marketplaces in 2014, with the federal government operating the SHOP marketplace in 33 states. This brief examines state decisions to enhance the value of SHOP marketplaces for small employers and finds that most have set predictable participation and eligibility requirements and will offer a competitive choice of insurers and plans. States also are seeking to facilitate small employers' shopping experience through online tools and access to personalized assistance. While not all SHOP marketplaces are yet functioning as intended, their establishment offers an opportunity to identify successful strategies for improving the affordability and accessibility of coverage for small employers.

\section{OVERVIEW}

To improve access to coverage for small employers, the Affordable Care Act introduces new small-group market reforms and establishes Small Business Health Options Program (SHOP) marketplaces—also known as exchanges—in each state. SHOP marketplaces are envisioned as online, one-stop-shopping portals that can aggregate the purchasing power of multiple small businesses; provide employers and employees with more transparent plan choices; and give small employers new options, like offering employees a choice of plans while setting a predictable contribution to employee coverage. ${ }^{1}$ To date, 17 states and the District of Columbia have established or plan to operate their own SHOP marketplaces in 2014, while the federal government is operating the SHOP marketplace in 33 states.

Compared with large firms, small employers have historically been less likely to offer comprehensive health insurance or a choice of plans, and their employees are more likely to be uninsured or underinsured. ${ }^{2}$ Past attempts to establish SHOP-like mechanisms through which small employers could pool their purchasing power to buy health insurance coverage have had mixed success with attracting adequate enrollment and keeping premiums competitive, in part 
because of the need to compete with existing coverage options for small employers and avoid adverse selection. ${ }^{3}$ To remedy these challenges and make SHOP marketplaces more attractive to small employers, the Affordable Care Act has set common rules for smallgroup insurers inside and outside the SHOP marketplace and made SHOP coverage the sole way certain small employers can qualify for a small business tax credit. ${ }^{4}$ The law will also eventually require all SHOP marketplaces to offer a feature known as "employee choice" - previously unavailable to most small employers-in which employers can allow their employees to choose from multiple health plans. ${ }^{5}$

This issue brief examines state action to implement SHOP marketplaces, focusing on state decisions to create features valuable to small employers (Exhibit 1). ${ }^{6}$ We find that all state-based SHOP marketplaces standardized SHOP eligibility and participation requirements, and nearly all will offer a competitive choice of plans, allow employers to give employees multiple plan choices while setting a predictable contribution toward coverage, and provide features to create a more convenient shopping experience.

While most states made policy and design decisions with an eye toward providing small employers with features they value, not all SHOP marketplaces are yet functioning as intended. Several state-based SHOP marketplaces have not yet opened for business or-along with the federal SHOP marketplace-have delayed key functionalities like online enrollment and employee choice. ${ }^{7}$ SHOP marketplaces will face additional start-up challenges attracting enrollment in the initial years. To be successful, they must provide better value than competing small-group coverage options outside the SHOP and attract small employers who do not currently offer coverage. ${ }^{8}$ Some states have also permitted small employers to renew their existing coverage prior to the opening of the SHOP marketplaces, thus potentially decreasing small employers' initial demand for coverage through the SHOP marketplaces. ${ }^{9}$ While similar mechanisms have been tried before, the availability of SHOP marketplaces in every state will provide an unprecedented opportunity to identify successful strategies for improving the affordability and accessibility of coverage for small employers.

\section{FINDINGS}

In establishing their SHOP marketplaces, states sought to promote predictability and value for small employers by standardizing participation requirements, offering a competitive range of insurers and plans, and allowing small employers to give their employees a choice of plans while setting a predictable contribution toward coverage. States also sought to facilitate the small employer shopping experience through online tools and access to personalized assistance. States and the federal government remain in different stages of launching their SHOP marketplaces and implementing key features intended to provide value for small employers.

\section{States Set Predictable SHOP Eligibility and Participation Requirements}

In structuring their SHOP marketplaces, states have generally sought to minimize disruption to the existing small-group market, while focusing on features that add value and predictability for small employers. ${ }^{10}$ Historically, states have defined small groups as consisting of up to 50 employees. The Affordable Care Act requires SHOP marketplaces to be open to businesses with 100 or fewer workers beginning in 2016, but gave states the option to limit eligibility to businesses with 50 or fewer workers until then. In 2014, all states chose to limit eligibility for their SHOP marketplaces to businesses with 50 or fewer full-time employees, allowing continuity with their existing definitions for small-group market size. ${ }^{11}$ Many also established minimum participation requirements, specifying the percentage of employees within any given group that must enroll in SHOP coverage to create a predictable standard, encourage broad participation, and mitigate concerns regarding adverse selection (i.e., the fear that healthy people will not sign up and the marketplaces will have a disproportionate number of people with health problems) ${ }^{12}$ (Exhibit 2). These standards-along with federal regulations requiring a one-month open enrollment period through SHOP for small employers who cannot meet minimum participation or contribution requirements-could improve the predictability and availability of coverage for small employers who have previously been denied coverage because they 


\section{Exhibit 1. Design Considerations to Enhance the Value of SHOP for Small Employers}

\begin{tabular}{ll}
\hline Design consideration & Description \\
\hline $\begin{array}{l}\text { Predictable eligibility and } \\
\text { participation requirements }\end{array}$ & $\begin{array}{l}\text { Eligibility and participation requirements for small-group coverage have typically varied from insurer } \\
\text { to insurer. Most states have chosen to apply a minimum participation requirement, which by federal } \\
\text { regulation must apply to all insurers participating in SHOP, increasing predictability for small businesses. }\end{array}$ \\
\hline Competition as price driver & $\begin{array}{l}\text { Competition can be a driver of increased choices and lower costs for employers. Most state SHOP } \\
\text { marketplaces will offer employers a choice of insurers and plans. }\end{array}$ \\
\hline $\begin{array}{l}\text { Employee choice while } \\
\text { maintaining employer's } \\
\text { predictable budgeting }\end{array}$ & $\begin{array}{l}\text { Employers are interested in offering their employees a choice of insurance plans, allowing their } \\
\text { employees to pick the best plan for their personal health and financial needs, while maintaining a } \\
\text { predictable budget for health insurance. States have attempted to balance these ideals in differing ways. }\end{array}$ \\
\hline $\begin{array}{l}\text { Convenient shopping } \\
\text { experience }\end{array}$ & $\begin{array}{l}\text { In order to be attractive to employers, SHOP marketplaces must be user-friendly, with educational } \\
\text { materials and easily accessible personalized assistance. Some features for helping small employers } \\
\text { understand their SHOP plan options are more common than others among states. }\end{array}$ \\
\hline
\end{tabular}

Source: Authors' analysis.

Exhibit 2. Minimum Participation Requirements in State SHOP Marketplaces

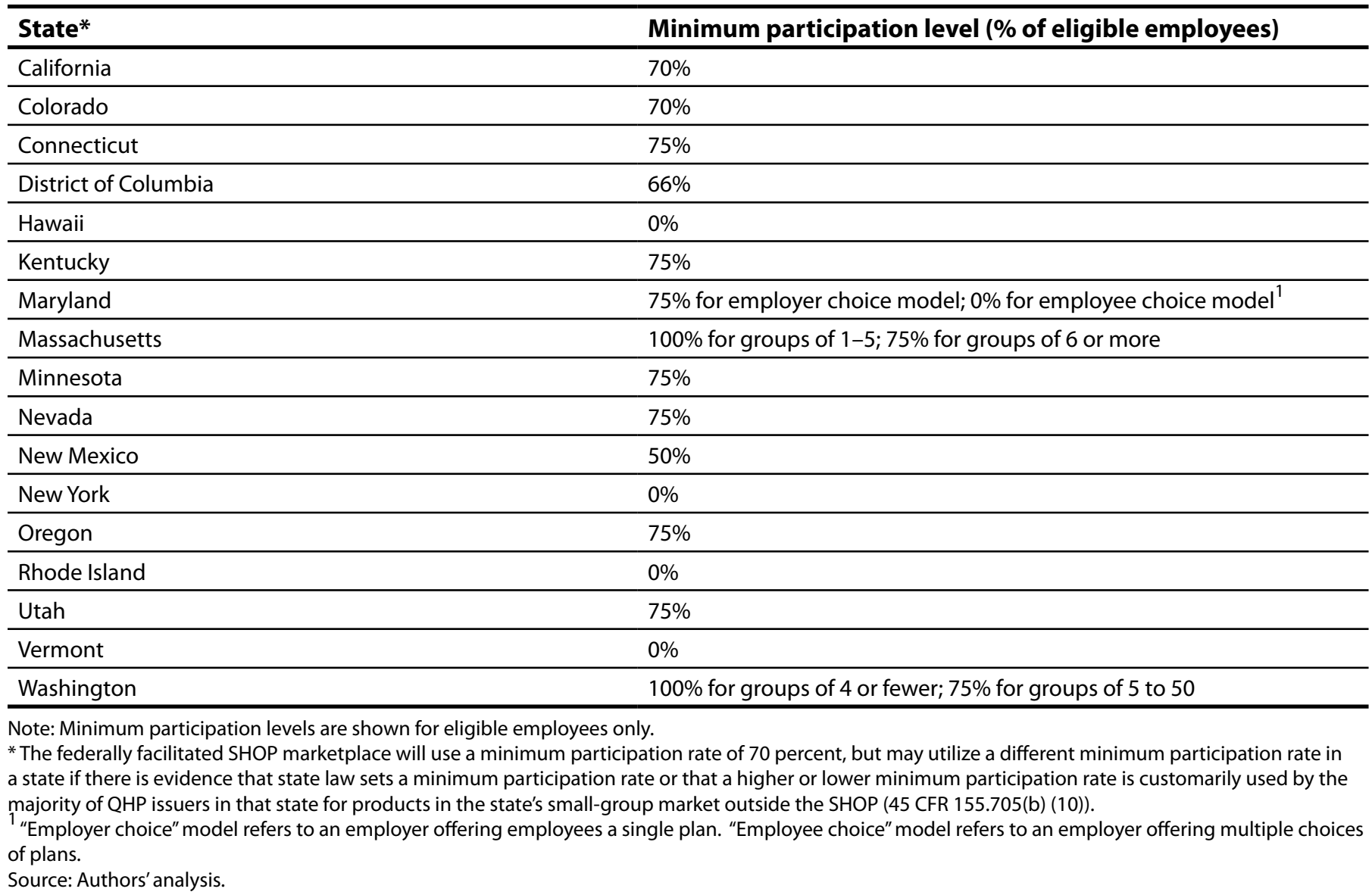


were unable to meet insurers' minimum participation or contribution standards. ${ }^{13}$

\section{SHOP Marketplaces Encouraged Plan Participation and Attracted Competitive Selection of Insurers and Plans}

Nearly all state-based SHOP marketplaces attracted enough competition to offer small employers and employees a choice of insurers and plans, across a range of coverage levels and in nearly every county (Exhibit 3). The number of insurers participating in the states ranged from one in Washington to 10 in New York. In all but four states-Minnesota, Nevada, New York, and Washington-the SHOP had participation from more than one insurer in every county. ${ }^{14}$ There was wide variation in the total number of plans offered, from 12 in Connecticut to 267 in the District of Columbia, with a broad selection of plans across the bronze, silver, gold, and platinum coverage levels, or metal tiers, outlined in the Affordable Care Act. ${ }^{15}$

The success of the SHOP marketplaces in attracting small employers will depend partly on how plan options in the SHOP marketplace compare with those outside the marketplace. ${ }^{16}$ Most states were able to attract at least one of the three largest insurers (measured by market share) in the state (Exhibit 4) ${ }^{17}$ Insurers' participation decisions may have varied by the design choices states made and by the existing characteristics of each state's small-group market. For example, all three of the largest carriers participated only in Maryland, Massachusetts, and the District of Columbia. The first two states required insurers to participate or offer plans in the SHOP, while D.C. created a single marketplace through which all individual and small-group coverage will be sold. ${ }^{18}$

\section{States Prioritized Employee Choice with Fixed Contributions for Small Employers}

The Affordable Care Act requires SHOP marketplaces to offer a feature known as "employee choice," in which employers choose a metal tier of coverage and then allow employees to select any plan from that tier. ${ }^{19}$ States may provide additional employee choice models which, subject to employers' selections, would allow employees to select from multiple metal tiers or from any plan offered through the SHOP. While small employers are less likely than larger employers to offer a choice of health insurance plans to their employees, a majority of those currently offering coverage find the possibility offering a choice of plans appealing. ${ }^{20}$ Employee choice represents a clear departure from the options available to most small employers today, both relieving employers of the challenge of finding a single plan that works for all of their employees' needs and preferences, and creating the potential for increased competition among insurers as they work to attract the enrollment of individual employees rather than relying on small employers as an intermediary for plan selections.

While the U.S. Department of Health and Human Services (HHS) delayed the employee choice requirement for states and the federally facilitated SHOP until 2015, ${ }^{21} 16$ states and the District of Columbia are planning to offer employee choice in their SHOP marketplaces in 2014. ${ }^{22}$ All states except California opted to provide small employers with a range of employee choice models beyond the federally required option in which employees select a plan from a metal tier chosen by the employer (Exhibit 5). Seven states-Hawaii, Minnesota, New York, Oregon, Rhode Island, Utah, and Vermont-opted to allow employers to give employees the choice of any plan on the SHOP marketplace.

In deciding how much employee choice to offer, states balanced options that provided the broadest possible choices-which some states felt would attract small employers - with concerns about adverse selection that could result if older or sicker employees disproportionately chose more comprehensive coverage. ${ }^{23}$ To mitigate such concerns, some states placed constraints on the coverage levels employers and employees could choose. For example, Colorado, Kentucky, and Oregon limited employers and employees' choice of plans to contiguous metal tiers, even while offering broad employee choice. Restricting plan choice to contiguous metal tiers is expected to limit adverse selection 
Exhibit 3. Plan Choice for Small Employers in State SHOP Marketplaces, 2014

\begin{tabular}{|c|c|c|c|c|c|c|c|}
\hline \multirow[b]{2}{*}{ State } & \multirow{2}{*}{$\begin{array}{l}\text { Number of } \\
\text { participating } \\
\text { insurers }\end{array}$} & \multicolumn{5}{|c|}{ Total number of plans } & \multirow{2}{*}{$\begin{array}{l}\text { More than one } \\
\text { insurer per } \\
\text { county? }\end{array}$} \\
\hline & & Bronze & Silver & Gold & Platinum & Total & \\
\hline California & 6 & 9 & 10 & 7 & 7 & 33 & $N A^{1}$ \\
\hline Colorado & 6 & 28 & 38 & 26 & 0 & 92 & Yes \\
\hline Connecticut & 3 & 5 & 3 & 4 & 0 & 12 & $\mathrm{Yes}^{2}$ \\
\hline District of Columbia & 4 & 18 & 89 & 112 & 48 & 267 & Yes $^{2}$ \\
\hline Hawaii $^{3}$ & 2 & 0 & 3 & 6 & 6 & 15 & Yes \\
\hline Kentucky & 4 & 6 & 8 & 8 & 2 & 24 & Yes \\
\hline Maryland $^{4}$ & 6 & 20 & 30 & 32 & 22 & 104 & Yes \\
\hline Massachusetts & 10 & 16 & 18 & 46 & 26 & 106 & Yes \\
\hline Minnesota & 3 & 10 & 23 & 24 & 6 & 63 & No \\
\hline Nevada & 2 & 1 & 5 & 5 & 2 & 13 & No \\
\hline New Mexico ${ }^{5}$ & 4 & 9 & 18 & 14 & 2 & 43 & $\mathrm{Yes}^{2}$ \\
\hline New York & 10 & 22 & 24 & 21 & 20 & 87 & No \\
\hline Oregon & 8 & 23 & 28 & 19 & 3 & 73 & Yes \\
\hline Rhode Island & 3 & 2 & 5 & 6 & 3 & 16 & Yes $^{2}$ \\
\hline Utah & 3 & 9 & 33 & 28 & 0 & 70 & Yes \\
\hline Vermont & 2 & 3 & 5 & 4 & 2 & 14 & $Y_{e s}^{2}$ \\
\hline Washington & 1 & 1 & 3 & 1 & 0 & 5 & No \\
\hline \multicolumn{8}{|c|}{$\begin{array}{l}\text { 1. In California, there was more than one insurer in every rating region. County-level data were not available. } \\
2 \text { Connecticut, the District of Columbia, New Mexico, Rhode Island, and Vermont required insurers to participate throughout the entire state or jurisdiction. } \\
3 \text { In addition to the } 15 \text { plan options shown here, Hawaii's SHOP marketplace offered } 12 \text { additional plan options in two benefit tiers, "7A" and "7B," for } \\
\text { employers subject to the Prepaid Health Care Act. } \\
4 \text { Represents health plans certified by Maryland's SHOP marketplace; may not reflect final plan offerings. Maryland delayed online enrollment in its } \\
\text { SHOP marketplace until fall } 2014 \text { for the plan year beginning on or after January 1, 2015, but planned to offer enrollment directly through SHOP insurers } \\
\text { beginning in April } 2014 \text {. } \\
5 \text { Prior to December 2013, the New Mexico SHOP marketplace had five participating insurers and } 57 \text { total plans. In December 2013, one insurer withdrew its } \\
\text { plans from both the individual and SHOP marketplaces because of its proposed acquisition by another insurer. } \\
\text { Source: Authors' analysis of SHOP plan offerings in state-based SHOP marketplaces. }\end{array}$} \\
\hline
\end{tabular}

Exhibit 4. Participation of Three Largest Insurers by Market Share, 2014

\begin{tabular}{|c|c|}
\hline Number of three largest insurers by market share participating in SHOP & States \\
\hline None of the three largest insurers participating & WA \\
\hline One of the three largest insurers participating & NV, NY, OR \\
\hline All of the three largest insurers participating & $\mathrm{DC}, \mathrm{MA}, \mathrm{MD}^{1}$ \\
\hline
\end{tabular}


Exhibit 5. State Decisions on State Employee Choice Selection Models, 2014

\begin{tabular}{|c|c|c|c|c|c|}
\hline \multirow[b]{2}{*}{ State $^{1}$} & \multirow[b]{2}{*}{ Single plan } & \multicolumn{4}{|c|}{ Employee choice plan selection models* } \\
\hline & & $\begin{array}{c}\text { One tier, } \\
\text { multiple insurers }\end{array}$ & $\begin{array}{c}\text { Multiple tiers, } \\
\text { one insurer }\end{array}$ & $\begin{array}{l}\text { Multiple tiers, } \\
\text { multiple insurers }\end{array}$ & $\begin{array}{l}\text { All tiers, } \\
\text { all insurers }\end{array}$ \\
\hline Colorado & $\mathrm{X}$ & $\mathrm{X}$ & $\mathrm{X}$ & $\mathrm{X}^{2}$ & - \\
\hline Connecticut & $\mathrm{X}$ & $\mathrm{X}$ & $\mathrm{X}$ & - & - \\
\hline Hawaii & - & $\mathrm{X}$ & - & $x^{3}$ & $x^{3}$ \\
\hline Kentucky & $\mathrm{X}$ & $\mathrm{X}$ & - & $x^{4}$ & - \\
\hline Maryland $^{5}$ & - & $\mathrm{X}$ & $\mathrm{X}$ & - & - \\
\hline Massachusetts & $\mathrm{X}$ & $x^{6}$ & $x^{6}$ & - & - \\
\hline New York & - & $\mathrm{X}$ & $x$ & $\mathrm{X}$ & $\mathrm{X}$ \\
\hline Oregon & $\mathrm{X}$ & $x$ & $x$ & $x^{2}$ & $\mathrm{X}^{8}$ \\
\hline Rhode Island & $x$ & - & - & - & $X$ \\
\hline Utah & - & $x$ & - & - & $X$ \\
\hline Vermont & - & $x$ & - & - & $X$ \\
\hline Washington $^{9}$ & $X$ & $X$ & - & - & - \\
\hline
\end{tabular}

Note: These data reflect state-based marketplace design decisions for policy or plan years beginning on or after January 1, 2014. These data do not identify the options that a state-based marketplace may be considering for future years.

* Employee choice models include: 1) allowing employers to choose a single metal tier and employees select plans from different insurers; 2) allowing employers to choose a single insurer and employees select plans at different metal tiers; 3 ) allowing employers to select multiple insurers and employees select plans from multiple insurers at different metal tiers; or 4) allowing employees to select any plan on the SHOP marketplace.

${ }^{1}$ The federally facilitated SHOP will not offer employee choice in 2014. Idaho will use the federal technology platform for its SHOP marketplace, limiting employers to a single plan option.

${ }^{2}$ In Colorado and Oregon, employees are limited to choosing plans on the SHOP marketplace on metal tiers that are adjacent to the reference plan chosen by the employer (i.e., if the employer selects a silver plan, employees can only choose a plan from among bronze, silver, and gold options).

3 In Hawaii, the two models are only available for employers not subject to the requirements of the Prepaid Health Care Act.

${ }^{4}$ In Kentucky, employers are limited to choosing plans on the SHOP marketplace on metal tiers that are contiguous (i.e., the employer may not select only the bronze and gold levels for employees).

${ }^{5}$ Maryland delayed online enrollment in its SHOP marketplace until fall 2014 for the plan year beginning on or after January 1, 2015, but planned to offer enrollment directly through SHOP insurers beginning in April 2014. Employee choice will not be available through the direct enrollment process.

${ }_{7}^{6}$ In Massachusetts, the employee choice model is expected to be available later in 2014.

7 In addition to the available models shown here, Nevada originally opted to offer the multi-tier, multi-insurer ("multi-insurer partnership") and all-tier, allinsurer options; however, those will not be available to employers in 2014 because carriers did not structure their plan offerings to allow those options.

8 In Oregon, this model is available only if the employer selects a gold plan as its reference plan.

9 In Washington, the SHOP marketplace will operate as a pilot program in 2014 with only one insurer.

Source: Authors' analysis.

that could result, for example, from healthier employees disproportionately choosing bronze plans while sicker or higher-risk employees select more comprehensive platinum plans. ${ }^{24}$

\section{Most States Allowed Employers to Provide a Fixed Contribution to Employee Coverage, but Mechanisms Varied}

In today's small-group market, employers typically contribute toward a single plan for all employees. ${ }^{25}$ The
SHOP marketplace offers employers a new value proposition: the ability to offer their workers a choice of plans while making a predictable contribution to coverage, regardless of the plan an employee chooses-this is also known as "defined contribution." 26 Defined contribution does not necessarily refer to the employer applying a flat dollar amount toward coverage, but typically allows employers to designate a percentage contribution toward one particular plan-known as a "reference plan"-from among the plans available to employees. 
If employees choose plans that are more expensive than the reference plan, they pay the difference. ${ }^{27}$ For 2014, 14 states and the District of Columbia allowed employers to set a predictable contribution toward coverage regardless of employees' choices (Exhibit 6). Five states allowed employers to contribute toward any plan selected by the employee, resulting in an employer contribution that varies based on the employee-selected plan.
Federal regulations allow premiums in the small-group market to be adjusted based on the allowable rating factors (age, geography, tobacco use, and family size) for each employee for plan years beginning January 1, 2014. In most states, employer contributions will be based on an employee-specific premium, also known as a "list bill," and will therefore vary by the employee's individual rating factors. To allow employers to provide an equal dollar contribution to all

\section{Exhibit 6. State Action on Employer Contribution Models in SHOP Marketplaces, 2014}

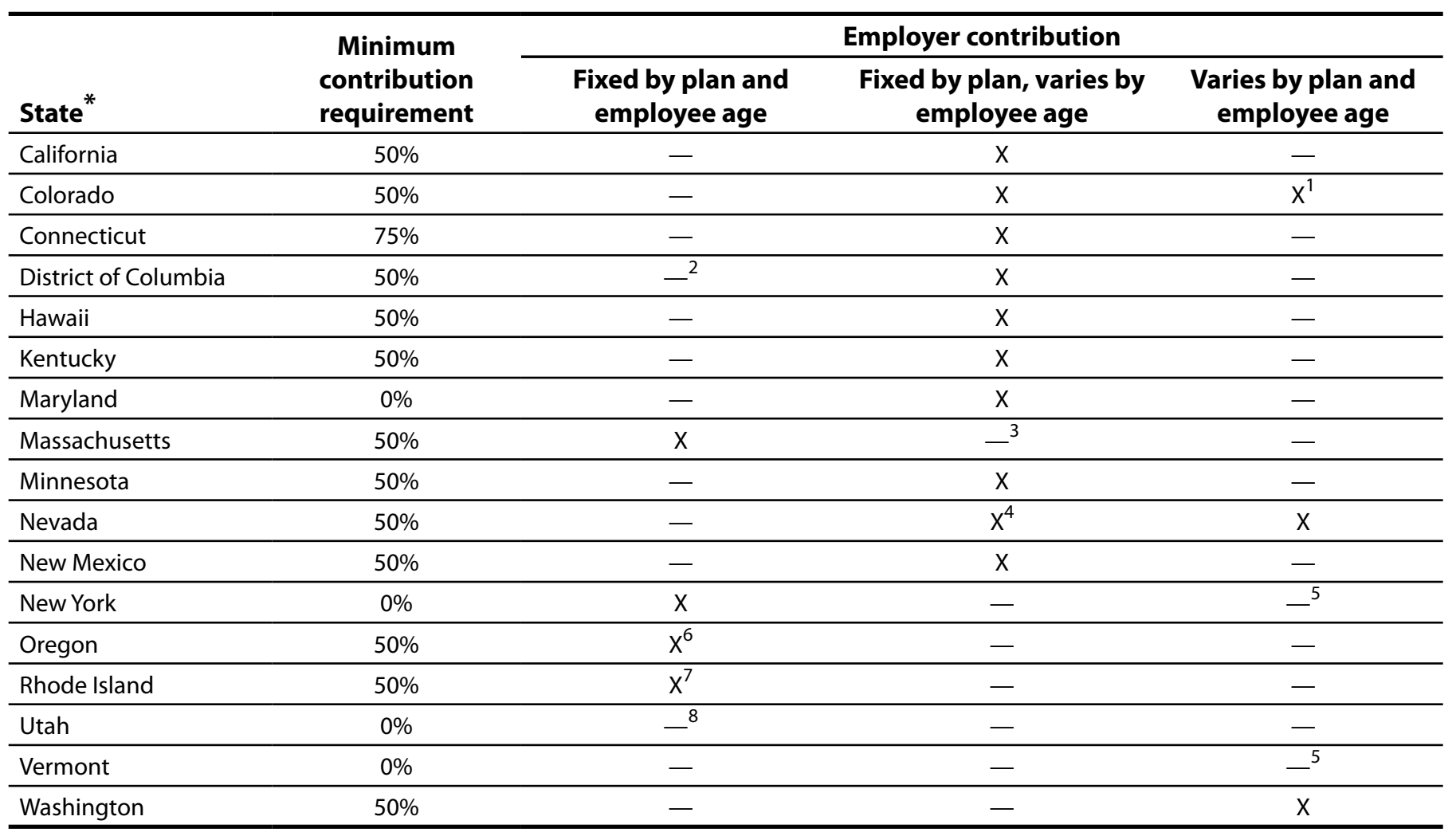

These data reflect state-based marketplace design decisions for policy or plan years beginning on or after January 1, 2014. These data may not reflect current functionality of the marketplaces and do not identify the options that a state-based marketplace may be considering for future years.

* When the federally facilitated SHOP offers employee choice in 2015, employer contributions will be calculated based on a percentage contribution for a reference plan selected from within a metal tier of coverage. Employers in all FF-SHOPs will be able to have their employees contribute the same amount toward premiums regardless of age (i.e., composite rating), or, in most states, employers will have the option to have employees contribute to premiums based on age (CMS, FF-SHOP Issuer Frequently Asked Questions, Oct. 2, 2013).

${ }_{1}^{1}$ Colorado allows employers to offer their contribution as a percentage, fixed dollar amount, or capped percentage of a list-billed premium.

2 The District of Columbia Health Benefit Exchange Board approved a method known as "Reallocated Composite Premium, with employees paying the difference in list billing between the reference plan and the plan they select" as the premium rating approach in the small-group marketplace, but was unable to implement this option for 2014 because of technological limitations.

${ }^{3}$ Massachusetts may allow employer contributions to vary by employee age under its "Dual-Triple" option, in which employers allow employees to select from among multiple plans offered by the same insurer.

${ }_{5}^{4} \mathrm{Nevada}$ also provides employers the option to choose the lowest-cost plan among those offered by the employer as the reference plan.

${ }^{5}$ In New York and Vermont, employers may contribute a percentage of premium or flat dollar amount toward any plan selected by the employee, but individual employee rates do not vary by age because of the states' pure community rating requirements.

${ }^{6}$ In Oregon, the employee contribution is based on the difference between the composite-rated premium for the selected plan and the employer contribution for the reference plan.

7 In Rhode Island, the employee contribution is based on the difference between the list-billed premium for the selected plan and the reference plans, added to the employee contribution for the reference plan.

${ }^{8}$ Utah allows employers to contribute a defined dollar amount toward each employee's coverage. The employee pays the employee-specific (age-rated) premium for the employee's selected plan, minus the employer's contribution.

Source: Authors' analysis. 
employees regardless of age, two states-Oregon and Rhode Island-developed an employer contribution methodology based on a reference plan for which an average ("composite") rate was calculated, allowing the same rate to be applied to every person in the employer group. ${ }^{28}$ At least three states-Colorado, Kentucky, Minnesota - and the District of Columbia, considered but did not initially choose to implement composite rating methodologies because of their technical complexity. ${ }^{29}$ New York and Vermont have pure community rating requirements that do not allow premiums to vary by age, an approach that also results in an equal contribution for all employees. To help workers afford their employer's offer of coverage, 11 states required employers to contribute a minimum percentage toward the employee-only premium. ${ }^{30}$

In contrast to a list-billing approach, a composite rating approach can also increase predictability for small employers if an employee joins or leaves the business, because the employer's contribution is based on a group average rather than the individual employee's premium. ${ }^{31} \mathrm{HHS}$ will require that if an insurer in the small-group market-including the SHOP marketplace - offers a composite premium, the composite premium would not change during the plan year even if the composition of the group changes. ${ }^{32}$

\section{SHOP Marketplaces Sought to Provide a Convenient Shopping Experience for Small Employers Using Online Tools and Personalized Assistance}

In developing their SHOP marketplaces, a number of states included features intended to create a more convenient shopping experience for small employers, although initial technological challenges in some states may have masked their intended effect, and it is too early to determine how these features may have improved small employers' shopping experience (Exhibit 7). Many state SHOP marketplaces offered online enrollment as of January $1,2014 .{ }^{33}$ At least 12 states and the District of Columbia allowed small employers to explore their coverage options without submitting information such as a tax identification number. Of these, at least seven-Connecticut,
Hawaii, Nevada, New York, Oregon, Rhode Island, and Utah - and the District of Columbia offered an online searchable plan-sorting tool, allowing small employers the ability to browse available plans by features such as premiums, metal tier, or insurer. ${ }^{34}$ Ten states and the District of Columbia provided a calculator to help employers assess their eligibility for the federal small businesses tax credit; the District of Columbia and Vermont offered a calculator to help employers calculate their number of full-time-equivalent employees for purposes of determining eligibility for the SHOP.

Even if all SHOP marketplaces achieve the goal of a streamlined online shopping experience, many small employers are still likely to need help selecting coverage options, and employees who have not previously had a choice of coverage are also likely to benefit from in-person assistance. Because 80 percent of small businesses currently work with agents or brokers and are likely to continue relying on their assistance, engaging the broker community will likely be critical to the SHOP's success. ${ }^{35}$ To help small employers find in-person help for enrollment, nearly every state offered an online directory of navigators, in-person assisters, agents, and brokers. In New York, for example, small employers can search for a navigator or broker

\section{Exhibit 7. Selected SHOP Features to Enhance Small Employer Purchasing Experience, as of January 1, 2014}

\begin{tabular}{|c|c|}
\hline Consumer-friendly feature ${ }^{1}$ & States \\
\hline $\begin{array}{l}\text { Anonymous browsing of } \\
\text { plan options }\end{array}$ & $\begin{array}{l}\mathrm{CA}, \mathrm{CT}, \mathrm{CO}, \mathrm{DC}^{2}{ }^{2} \mathrm{HI}, \mathrm{MN}, \mathrm{NV}, \\
\mathrm{NM}, \mathrm{NY}, \mathrm{OR}, \mathrm{RI}, \mathrm{UT}, \mathrm{VT}, \\
\text { FF-SHOP states }\end{array}$ \\
\hline $\begin{array}{l}\text { Small business tax credit } \\
\text { calculator }\end{array}$ & $\begin{array}{l}\mathrm{CA}, \mathrm{CO}, \mathrm{DC}, \mathrm{HI}, \mathrm{KY}, \mathrm{MD}, \mathrm{MN} \text {, } \\
\mathrm{NV}, \mathrm{NY}, \mathrm{RI}, \mathrm{VT}\end{array}$ \\
\hline $\begin{array}{l}\text { Full-time-equivalent } \\
\text { employee calculator }\end{array}$ & DC, VT \\
\hline $\begin{array}{l}\text { Portal for agents and } \\
\text { brokers to manage small } \\
\text { business accounts }\end{array}$ & $\begin{array}{l}\text { CA, CO, DC, HI, MA, NV, NY, } \\
\text { OR, RI, UT, VT }\end{array}$ \\
\hline \multicolumn{2}{|c|}{$\begin{array}{l}\text { Note: Features may change or be periodically unavailable as states further } \\
\text { develop their SHOP marketplaces. } \\
1 \text { The federal SHOP marketplace website allows employers to review plan } \\
\text { options by zip code. In addition, the federal SHOP is currently developing } \\
\text { a small business tax credit and full-time-equivalent employee calculator, } \\
\text { but does not currently have a portal available to agents and brokers. } \\
2 \text { In the District of Columbia, an email address must be entered to browse } \\
\text { plans. } \\
\text { Source: Authors' review of SHOP websites as of January 1, } 2014 \text {. }\end{array}$} \\
\hline
\end{tabular}


based on factors such as geography, insurer affiliations, and agency name. ${ }^{36}$ Eleven states and the District of Columbia also provided agents and brokers with a separate portal through which they could enroll, track, and manage their clients. Most states allowed insurers to set compensation rates for brokers. ${ }^{37}$

\section{DISCUSSION}

If successfully implemented, SHOP marketplaces may encourage more small employers to maintain coverage or offer health benefits to employees for the first time. SHOP marketplaces face important start-up challenges, including the need to compete with other coverage options available to small employers and implement the technology needed to bring their design decisions to fruition. Moreover, the limited enrollment period and early challenges with the individual health insurance marketplaces has made them a more urgent priority for many states, which can now turn their attention to improving their SHOP marketplaces. Small employers do not have a deadline by which they need to enroll in coverage, and many may have chosen to renew their existing coverage prior to the availability of the SHOP, which may also be reducing initial demand for SHOP coverage in some states. The degree to which small employers find the SHOP marketplace user-friendly and cost-effective will be critical factors in determining whether they offer coverage through the SHOP, outside the SHOP, or not at all.

In 2014, most state-based SHOP marketplaces will offer small employers a key feature generally not available outside the SHOP: the ability to offer employees a choice of plans from multiple insurers while making predictable contributions toward coverage. States have varied in their implementation of employee choice and contribution models. As employee choice options become available in both state and federally facilitated SHOP marketplaces in 2015, state and federal policymakers should evaluate enrollment patterns and consumer experiences both inside and outside the SHOP to better understand which models are most attractive to employers and employees, as well as how insurers respond.
In contrast to the current market, where small employers must attempt to choose a plan that works for the different health needs and preferences of all their employees, employee choice creates an experience more akin to the individual market, in which insurers are more likely to compete based on the individual needs and preferences of individual employees. To make employee choice possible, SHOP marketplaces must develop a mechanism to allow employers to contribute to each employee's individual premium. As a result, some small-business employees may experience the effects of age rating for the first time, with older employees paying more and younger employees paying less than they would have under composite billing. Some states have attempted to develop models that mimic group coverage by allowing employers to contribute equally to all workers regardless of their age, but such models are challenging to implement. Policymakers should monitor the effects of contribution methodologies on employees of various ages, as well as how the movement toward individual employee choice in coverage affects employer and employee decisions to offer and enroll in small-group coverage. SHOP marketplaces could help remedy the lack of competition in most states' small-group markets-and drive down premiums - by encouraging insurer participation and offering a range of easily comparable plan choices to small employers and employees. Early indications suggest that there will be a selection of plans in most state SHOP marketplaces, with lower-thanprojected premiums. ${ }^{38}$ Employee choice, where available, may spur additional competition in the smallgroup market by compelling insurers to compete for the business of individual employees. Some employee choice models - such as those that allow employees to choose among multiple carriers-may foster more competition than others, such as those that allow employers to offer multiple plans from a single carrier. In areas where there is not enough competition, states may wish to consider formal mechanisms to require or encourage insurer participation.

The implementation of SHOP marketplaces has been characterized by a common interest among state 
and federal policymakers in providing value-added features to small employers, although the provision of specific features has varied from state to state. While SHOP marketplaces in every state will have similar core elements, their success in enrolling small businesses will depend not only on how employers perceive the value of features such as employee choice and the small business tax credit, but also on the cost of available plans; ease of use of the marketplace for employers, agents, and brokers; and available options outside the marketplace. Currently, few states have reported SHOP enrollment statistics, but future evaluations should seek to determine the relative importance of various SHOP characteristics in attracting small-employer enrollment. The launch of SHOP marketplaces in all 50 states and the District of Columbia offers policymakers an important opportunity to identify successful strategies for improving the accessibility and affordability of coverage in the small-group market.

\section{Methodology}

This issue brief examines policy and design decisions made by the 17 states (California, Colorado, Connecticut, Hawaii, Kentucky, Maryland, Massachusetts, Minnesota, Mississippi, Nevada, New Mexico, New York, Oregon, Rhode Island, Utah, Vermont, and Washington) and the District of Columbia that chose to establish and operate state-based Small Employer Health Options Program (SHOP) marketplaces for 2014. Idaho and Mississippi have received conditional approval from the Department of Health and Human Services to operate state-based SHOP marketplaces. However, Idaho's SHOP will operate as a "supported state-based marketplace" in 2014, relying on the federal information technology infrastructure as the state builds its own system. Mississippi did not receive conditional approval to operate a state-based SHOP marketplace until October 1, 2013, and its SHOP marketplace is expected to open in 2014; policy decisions for operating its SHOP have not been made public. Although not reviewed for purposes of this paper, states in which the federal government is managing the SHOP marketplace have discretion over certain policy decisions affecting the operation of the SHOP in their state.

Our findings are based on public information — such as state laws, regulations, subregulatory guidance, marketplace solicitations, and other materials related to marketplace development-and interviews with state regulators. The resulting assessments of state action were confirmed by state officials. Our analysis of consumerfriendly features is based on a review of SHOP websites as of January 1, 2014. These features may change or be periodically unavailable as states continue to develop their SHOP marketplaces. 


\section{Notes}

1 T. S. Jost, "Employers and the Exchanges Under the Small Business Health Options Program: Examining the Potential and the Pitfalls," Health Affairs, Feb. 2012 31(2):267-74; and, J. R. Gabel, H. Whitmore, J. Pickering et al., "Small Employer Perspectives on the Affordable Care Act's Premiums, SHOP Exchanges, and SelfInsurance," Health Affairs, Nov. 2013 32(11):2032-39.

2 R. Robertson, K. Stremikis, S. R. Collins, M. M. Doty, and K. Davis, Jobs Without Benefits: The Health Insurance Crisis Faced by Small Businesses and Their Workers (New York: The Commonwealth Fund, Nov. 2012); and E. K. Wicks, Health Insurance Purchasing Cooperatives (New York: The Commonwealth Fund, Nov. 2002).

3 Wicks, Health Insurance Purchasing Cooperatives, 2002.

445 CFR § 144, 147, 150, 154, 155, and 156; and U.S. Department of Health and Human Services, "Will I Qualify for Small Business Health Care Tax Credits?" (Washington, D.C.: DHHS), https://www.healthcare. gov/will-i-qualify-for-small-business-health-caretax-credits/. Tax credits are available for employers with fewer than 25 employees making an average of under $\$ 50,000$. Employers must contribute at least half of their employees' premiums.

5 The Affordable Care Act requires SHOP marketplaces to offer a feature known as "employee choice" in which employers choose a metal tier of coverage and allow employees to select any plan from that tier. The U.S. Department of Health and Human Services (HHS) delayed this requirement for state-based marketplaces and will not offer employee choice in the federally facilitated SHOP marketplace until 2015. While employee choice will be available to all states with federally facilitated SHOP marketplaces in 2015, HHS has indicated that it may propose allowing these states to opt out of offering employee choice in their federally facilitated SHOP marketplaces in future rulemaking (2015 Notice of Payment Parameters).

6 Gabel, Whitmore, Pickering et al., "Small Employer Perspectives," 2013.

7 As of March 2014, not all state-based SHOP marketplaces were open for enrollment or had deployed all intended functionalities. In Maryland, Mississippi, and Oregon, there was no functioning SHOP marketplace online or via paper application. Maryland delayed online enrollment in its SHOP marketplace until fall 2014 for the plan year beginning on or after January 1, 2015, but planned to offer enrollment directly through SHOP insurers beginning in April 2014. Mississippi had conditional approval to operate a state-based SHOP exchange on October 1,2013, with an anticipated opening date in 2014, but does not yet have an open marketplace. Other states delayed certain functionalities: California suspended online enrollment in its SHOP marketplace in February 2014 to make improvements to the online enrollment technology; Massachusetts delayed the availability of employee choice until later in 2014; and Vermont's SHOP did not allow online payment until March 2014. Washington's SHOP marketplace is operating in only two counties in the state because of a lack of insurer participation. Idaho's SHOP will operate as a "supported state-based marketplace" in 2014, relying on the federal information technology infrastructure as the state builds its own system. HHS delayed the "employee choice" requirement for state-based SHOP marketplaces, and will not offer employee choice in the federally facilitated SHOP marketplace, until 2015. Additionally, HHS is considering proposing through future rulemaking specific circumstances under which states could recommend that a SHOP modify the employee choice provision in 2015. On November 27, 2013, the federal government announced a one-year delay in online enrollment through the federal SHOP exchange until November 2014. For more detailed information on available enrollment options for small employers in the federal SHOP marketplace, see, e.g., U.S. Department of Health and Human Services, "A Direct New Path to SHOP Marketplace Coverage" (Washington, D.C.: HHS, Nov. 2013).

8 In most states, small employers will be able to enroll in small-group coverage inside or outside of the SHOP marketplace; the District of Columbia and Vermont will eventually require all small-group coverage to be sold through the SHOP marketplace. While small employers' decisions to offer coverage in general are not the focus of this brief, small employers must weigh a number of factors when deciding whether to offer coverage, such as the value of offering health benefits as an employee recruitment and retention strategy, the cost and tax benefits of offering employer-sponsored coverage, and administrative resources needed to administer health benefits. Small employers with 50 or fewer full-time-equivalent employees are not required to offer coverage under the Affordable Care Act, and may enroll in the SHOP marketplace at any time throughout the year. 
C. Monahan and S. Corlette, “The Affordable Care Act's Early Renewal Loophole: What's at Stake and What States Are Doing to Close It," The Commonwealth Fund Blog, Aug. 22, 2013. Federal guidance issued in March 2014 will allow renewals of existing policies in the individual and small-group insurance markets that do not comply with the Affordable Care Act through October 2016, subject to state approval, although the impact of early renewals of noncompliant policies is estimated to be small. (S. R. Collins, "Impact of Extending Policy on Cancelled Plans Likely Small," The Commonwealth Fund Blog, March 7, 2014).

10 S. Dash, K. Lucia, K. Keith et al., Implementing the Affordable Care Act: Key Design Decisions for State-Based Exchanges (New York: The Commonwealth Fund, July 2013).

11 Members of Congress and designated staff will be eligible to purchase their coverage through the District of Columbia SHOP exchange.

12 Dash, Lucia, Keith et al., Implementing the Affordable Care Act, 2013.

1345 C.F.R. $\S 147.104$.

${ }^{14}$ We examined insurer participation by county instead of by region because the default qualified health plan definition of service area is a county. Insurers also may elect to participate at the zip-code level. Examining competition by rating region could overstate a consumer's actual plan choices.

15 The new marketplaces must offer plans in four categories or "metal tiers" based on the percentage of medical costs covered: bronze (covering an average of $60 \%$ of a person's annual medical costs), silver (70\% of costs), gold (80\% of costs), and platinum ( $90 \%$ of costs). The Affordable Care Act requires insurers to offer plans at least at the silver and gold metal tiers in every marketplace, but states may require insurers to offer additional coverage levels.

16 Gabel, Whitmore, Pickreign et al., "Small Employer Perspectives," 2013.

17 Kaiser Family Foundation, "State Health Indicators: Small Group Insurance Market Competition" (Washington, D.C.: Henry J. Kaiser Family Foundation, Nov. 2012).
18 In Massachusetts, insurers with 5,000 or more lives in the individual and small-group market (combined) must submit a plan to the marketplace for consideration. Maryland required insurers to participate in the marketplace if their reported total aggregate annual earned premiums are $\$ 20$ million or more in the small-group market. The District of Columbia created a single marketplace through which all individual and small-group coverage will be sold. The federal government requires that an insurer may participate in the federal individual marketplace only if they or another insurer in the same insurer group participate in the federally facilitated SHOP, unless neither the insurer nor any other insurer in the same insurer group has a share of state small-group market greater than $20 \%$. California initially instituted a provision requiring insurers submitting bids in the individual marketplace to also submit bids for the SHOP exchange before reversing that policy in July 2013.

1945 C.F.R. $§ 155.705(b)(2)$.

${ }^{20}$ Gabel, Whitmore, Pickreign et al., "Small Employer Perspectives," 2013.

21 U.S. Department of Health and Human Services, "Patient Protection and Affordable Care Act; Establishment of Exchanges and Qualified Health Plans; Small Business Health Options Program," Federal Register, March 11, 2013 78(47):15553, 15557, www.gpo. gov/fdsys/pkg/FR-2013-03-11/pdf/2013-04952.pdf; and U.S. Department of Health and Human Services "HHS Notice of Benefit and Payment Parameters for 2015," Federal Register, March 11, 2014 79(47):13748, https:// federalregister.gov/a/2014-05052. Dash, Lucia, Keith et al., Implementing the Affordable Care Act, 2013.

23 Personal correspondence with exchange official, Rhode Island, May 2013 (on file with authors).

24 See, e.g., California Health Benefit Exchange, Board Recommendation Brief: Employer and Employee Choice in the Small Employer Health Options Program (SHOP). (Sacramento, Calif.: California Health Benefit Exchange, Oct. 2012).

25 J. Kingsdale, "Design Considerations in Structuring Employee Choice for SHOP Exchange" (Princeton, N.J.: Robert Wood Johnson Foundation, State Health Reform Assistance Network, Dec. 2012). 
26 For a detailed discussion of employer contribution models, see J. Kingsdale and M. Hegemann, "Premium Allocation and Employer Contribution Strategies for SHOP" (Princeton, N.J.: Robert Wood Johnson Foundation, State Health Reform Assistance Network, July 2013).

27 Two states, Colorado and Washington, did not have the capability to allow employers to select a reference plan. In Utah, employers are allowed to contribute a defined dollar amount toward any plan selected by the employee.

28 Kingsdale and Hegemann, "Premium Allocation," 2013. Extending this calculated composite approach to dependent coverage has proven to be challenging, in part because take-up varies greatly among dependents and may require frequent recalculation of the "average" premium.

29 Personal correspondence with marketplace officials in the District of Columbia, Colorado, Kentucky, and Minnesota (on file with authors).

30 Employers must contribute 50\% toward employee coverage in order to claim the small business tax credit through the marketplaces.

31 Kingsdale and Hegemann, "Premium Allocation," 2013.

32 This composite rating requirement will not apply in the federal SHOP marketplace under the employee choice model. U.S. Department of Health and Human Services "HHS Notice of Benefit and Payment Parameters for 2015," Federal Register, March 11, 2014 79(47):13749, 13798, https://federalregister.gov/a/2014-05052.

33 California, Maryland, Mississippi, and Oregon were not offering online enrollment as of March 1, 2014.

34 Online search tools for health plans may be available even if online enrollment is not available in a SHOP marketplace.

35 Gabel, Whitmore, Pickreign et al., "Small Employer Perspectives," 2013.

36 New York State of Health, "Find Broker/Navigator (Optional)," available at: https://nystateofhealth.ny.gov/ agent/hx_brokerSearch.

37 Dash, Lucia, Keith et al., Implementing the Affordable Care Act, 2013.
38 U.S. Department of Health and Human Services, Assistant Secretary for Planning and Evaluation, "Market Competition Works: Proposed Silver Premiums in the 2014 Individual and Small Group Markets Are Nearly 20\% Lower Than Expected" (Washington, D.C.: DHHS, ASPE, July 2013). 


\section{About the Authors}

Sarah J. Dash, M.P.H., is a research fellow at the Georgetown University Health Policy Institute's Center on Health Insurance Reforms, where her principal research focus is comprehensive monitoring of state health insurance marketplace implementation. She also focuses on the intersection of public and private health insurance with delivery system reforms. Previously, she was a senior health policy aide on Capitol Hill. Dash earned her master's degree in public health from Yale University.

Kevin W. Lucia, J.D., M.H.P., is a senior research fellow at the Georgetown University Health Policy Institute's Center on Health Insurance Reforms. He focuses on the regulation of private health insurance, with an emphasis on analyzing the market reforms implemented by federal and state governments in response to the Affordable Care Act. Lucia received his law degree from the George Washington School of Law and his master's degree in health policy from Northeastern University.

Amy Thomas is a research associate at the Georgetown University Health Policy Institute's Center on Health Insurance Reforms. Previously, she worked at MDwise, a Medicaid managed care organization, where she managed the company's qualified health plan applications for Indiana's health insurance marketplace.

Editorial support was provided by Deborah Lorber. 